La revue La revue pour l'histoire du CNRS

8 | 2003

Aux origines de l'Homme

Dictionnaire biographique d'archéologie

Eve Gran-Aymerich. Préface de Jean Leclant. CNRS ÉDITIONS, Paris, 2001

Muriel Le Roux

\title{
CpenEdition
}

Journals

Édition électronique

URL : https://journals.openedition.org/histoire-cnrs/416

DOI : $10.4000 /$ histoire-cnrs.416

ISSN : 1955-2408

Éditeur

CNRS Éditions

Édition imprimée

Date de publication : 5 mai 2003

ISBN : 978-2-271-06068-6

ISSN : $1298-9800$

Référence électronique

Muriel Le Roux, "Dictionnaire biographique d'archéologie », La revue pour I'histoire du CNRS [En ligne], 8 | 2003, mis en ligne le 07 mars 2006, consulté le 20 mai 2021. URL : http://journals.openedition.org/ histoire-cnrs/416 ; DOI : https://doi.org/10.4000/histoire-cnrs.416

Ce document a été généré automatiquement le 20 mai 2021

Comité pour l'histoire du CNRS 


\section{Dictionnaire biographique d'archéologie}

Eve Gran-Aymerich. Préface de Jean Leclant. CNRS ÉDITIONS, Paris, 2001

Muriel Le Roux

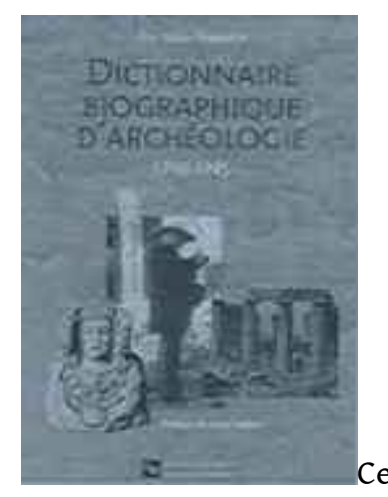

Ce dictionnaire biographique d'archéologie complète un autre travail tout aussi important publié sous le titre: Naissance de l'archéologie moderne, 1798-1945, édité en 1998 également par CNRS ÉDITIONS. Il y a quelque chose de vertigineux qui se dégage de la lecture de ces deux ouvrages complémentaires et indissociables: la somme du travail de recherche accomplie. Se lancer dans une telle aventure peut sembler irréaliste, arriver à soutenir le pari force le respect, car rares sont aujourd'hui les chercheurs qui se lancent seuls dans la rédaction d'un dictionnaire. L'attention accordée à l'histoire de la recherche scientifique ne se dément pas depuis une bonne dizaine d'années, mais les chercheurs des sciences humaines sont moins enclins que leurs collègues scientifiques à se pencher sur l'histoire de leur discipline. Voilà pourquoi le "dictionnaire Gran-Aymerich » est important. C'est un répertoire alphabétique. Il est composé d'environ huit cents notices bio-bibliographiques d'archéologues mais aussi de philologues, d'historiens, d'amateurs éclairés comme Agatha Mallowan Christie, tous chercheurs passionnés qui se sont intéressés au passé des pays méditerranéens, tout comme au passé de la Mésopotamie, de la Perse et de l'Anatolie. Les notices des Français sont certes majoritaires, mais Américains et Européens (Allemands, Grecs, Britanniques, Italiens) sont dignement représentés et confèrent à l'ouvrage une dimension internationale. Des fondateurs de la discipline aux 
contemporains, tous on bénéficié de la même attention. Reprenant les principes d'une mise en contexte des acteurs en passant par l'histoire politique, diplomatique, institutionnelle, on voit au fil des notices l'archéologie prendre son essor. De l'expédition d'Égypte des Français en 1798 jusqu'à 1945, se côtoient voyageurs, explorateurs, diplomates, artistes architectes ouvrant la voie aux archéologues, historiens, épigraphes, numismates... Naturalistes, préhistoriens, géologues, après qu'ils eurent démontré, aux alentours de 1850, l'ancienneté de la présence de l'Homme dans ces régions, ont proposé une autre vision du monde ancien ; c'est la raison pour laquelle ils sont aussi nombreux dans ce dictionnaire. La définition du corpus des notices a révélé avec une particulière acuité, nous explique l'auteure, la difficulté de parvenir à une définition aussi précise que possible du champ disciplinaire. Pourtant, en offrant une possibilité de circulation à la fois diachronique et chronologique émerge une histoire de la discipline dans l'entrelacs des autres disciplines des sciences humaines.

Ouvrage technique, ce dictionnaire, par la qualité d'écriture de son auteure, évite l'écueil de la sécheresse de l'énumération factuelles de dates et de faits. Chaque notice raconte plus qu'une vie, incite au voyage, chaque notice est un roman. Cet instrument de recherche scientifique rappelle que l'enquête archéologique, par son ambition: raconter le passé de l'humanité, procure du rêve à chacun d'entre nous. Indiana Jones a encore de beaux jours devant lui.

\section{INDEX}

Mots-clés : archéologie

\section{AUTEUR}

\section{MURIEL LE ROUX}

Chargée de recherche, IHMC - CNRS 